\title{
Adults with diabetes mellitus in Newfoundland and Labrador: a population-based, cross-sectional analysis
}

\author{
Julia Lukewich RN PhD, Richard Buote MSc, Shabnam Asghari MD PhD, Kris Aubrey-Bassler MSc MD, \\ John Knight PhD, Maria Mathews PhD
}

\section{Abstract}

Background: Although the province of Newfoundland and Labrador has the highest rates of chronic disease in Canada, the current state of many chronic diseases in the province, including diabetes mellitus, has not been well explored. We profiled the demographic characteristics associated with, and the management of, diabetes in Newfoundland and Labrador, including any rural-urban differences.

Methods: We performed a population-based, cross-sectional analysis using data from the provincial Chronic Disease Registry for fiscal year 2015/16. Patients in the study sample were 20 years of age or older, with documented identifiers for age, sex and geographic location. We examined demographic characteristics, results of screening and diabetes clinical tests (glycated hemoglobin $\left[\mathrm{HbA}_{1 \mathrm{c}}\right]$, low-density lipoprotein [LDL] cholesterol and urine albumin-to-creatinine ratio) and hospitalization rates. We described and compared demographic, clinical and hospitalization variables across urban and rural residents of the province.

Results: The study sample consisted of 66325 individuals with diabetes in Newfoundland and Labrador (mean age 64.1 yr; $56.3 \%$ rural residents). Larger proportions of rural than urban residents with diabetes were aged 65 to 79 years $(41.2 \%$ v. $37.5 \%)$, were female (50.2\% v. $48.7 \%)$ and were identified as having the disease by laboratory tests only (19.6\% v. $13.1 \%)$. Rural residents had worse clinical test outcomes than their urban counterparts, specifically with respect to $\mathrm{HbA}_{1 \mathrm{c}}$ (mean and standard deviation [SD], $7.41 \%$ [SD 1.49] v. 7.26\% [SD 1.50]) and LDL cholesterol (mean 2.46 [SD 0.95] v. mean 2.36 [SD 0.94] mmol/L). A total of 13.7\% of individuals were admitted to hospital during the cohort year, with slightly more rural residents admitted for renal disease (standardized difference $0.021,95 \%$ confidence interval 0.005 to 0.036 ).

Interpretation: For many individuals with diabetes in Newfoundland and Labrador, recommended targets for diabetes management are not being met, and residents in rural areas have poorer clinical outcomes. To inform the development and implementation of targeted provincial strategies for chronic disease management, further research is needed to determine how outcomes relate to the availability of primary health care services.

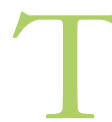
he province of Newfoundland and Labrador has some of the highest rates of chronic disease in Canada, with more than $60 \%$ of individuals having at least 1 chronic disease. ${ }^{1}$ The prevalence of diabetes mellitus increases with age, and Newfoundland and Labrador currently has a higher median age and a more rapidly aging population than any other province or territory. ${ }^{2}$ The relation between age and diabetes prevalence is primarily due to type 2 diabetes, which makes up the majority of diabetes cases in Canada and is most often diagnosed in adults over the age of $25.3,4$

The prevalence and economic burdens associated with diabetes in Newfoundland and Labrador are expected to grow, with an anticipated increase in prevalence of $23 \%$ over the next decade. ${ }^{5}$ Furthermore, the geographic distribution of the province's population is unique, in that about $47 \%$ of individuals live in rural regions. ${ }^{6}$ This presents challenges with respect to access to care, continuity of care, and the planning and implementation of diabetes programs.
Previous literature has described the prevalence and management of diabetes in Canada; $;, 5$ however, Newfoundland and Labrador lags behind other provinces and territories in examining this widespread chronic disease. There is a critical need to examine diabetes at the provincial level to inform the development of initiatives and strategies targeting areas of diabetes management that require attention. Recently, the Newfoundland and Labrador Centre for Health Information developed the Chronic Disease Registry, a new database that centralizes data for diabetes and other chronic diseases from various sources such as the Canadian Chronic Disease

\section{Competing interests: None declared.}

This article has been peer reviewed.

Correspondence to: Julia Lukewich, jlukewich@mun.ca

CMAJ Open 2020. DOI:10.9778/cmajo.20190233 
Surveillance System (CCDSS) and provincial laboratory test data. ${ }^{7}$ We aimed to profile the current state of adult diabetes prevalence and management in Newfoundland and Labrador using the Chronic Disease Registry.

\section{Methods}

\section{Study design}

We conducted a population-based, cross-sectional study to profile the current state of diabetes management across Newfoundland and Labrador. We used laboratory and hospitalization data from the 2015 fiscal year (Apr. 1, 2015Mar. 31, 2016).

\section{Participants}

We included individuals with type 1 or type 2 diabetes aged 20 years or older identified from the provincial Chronic Disease Registry. We included only those aged 20 years or older because Diabetes Canada recommends that management for adults with diabetes should occur in the community, in primary care settings, whereas diabetes management for children should occur within a pediatric team. ${ }^{8-10} \mathrm{We}$ included in our analyses all individuals who were living with a prevalent case of diabetes, as of the end of the 2015 fiscal year (i.e., Mar. 31, 2016).

\section{Data sources}

We acquired all data for this study from the Newfoundland and Labrador Centre for Health Information in July 2017. Specifically, we used data from the Chronic Disease Registry (a registry established in 2017 that synthesizes information from the CCDSS and medical laboratory data to identify patients with new and existing chronic disease). ${ }^{7}$ The Chronic Disease Registry includes, for all cases of diabetes in Newfoundland and Labrador, data from the Provincial Meditech Database (e.g., laboratory test data), the Provincial Discharge Abstract Database (e.g., hospitalization data), the Medical Care Plan Claims Database, the Medical Care Plan Beneficiary Registration Database and the Provincial Mortality System. The registry replaced and includes data from the Provincial Diabetes Database, with a look-back period to 1994, although laboratory data were not added to the registry until 2009. The registry includes information about patient management, health services, health outcomes and associated costs; it informs policy- and decision-making, program planning and monitoring.

The Chronic Disease Registry identifies and classifies individuals with diabetes using the CCDSS case definition, a laboratory case definition or both. The CCDSS case definition is based on at least 1 hospital admission or at least 2 physician visits with a diabetes diagnosis code from either the 9th revision of the International Classification of Diseases (ICD-9) or the 10th revision of the International Statistical Classification of Diseases and Related Health Problems (ICD-10) (i.e., ICD-9, 250; ICD-10, E10-E14) within a 2-year period. ${ }^{11}$ ICD-9 codes are used in the physician billing database and do not distinguish between type 1 and type 2 diabetes; therefore, the Chronic Disease Registry does not differentiate between the 2 types.

To identify people with diabetes, the CCDSS links provincial health insurance registry records with physician billing claims and hospital discharge abstract records. ${ }^{12}$ The laboratory case definition for diabetes requires any 2 of the following test results in a 2-year period: fasting plasma glucose greater than or equal to $7 \mathrm{mmol} / \mathrm{L}$, glycated hemoglobin $\left(\mathrm{HbA}_{\mathrm{cc}}\right)$ greater than or equal to $6.5 \%, 2$-hour plasma glucose in a 75 -g oral glucose tolerance test greater than or equal to $11.1 \mathrm{mmol} / \mathrm{L}$ or random plasma glucose greater than or equal to $11.1 \mathrm{mmol} / \mathrm{L} .{ }^{12}$ The CCDSS case definition has been validated for Canadian populations. ${ }^{13,14}$ The addition of laboratory data can improve surveillance that relies upon administrative data alone. ${ }^{15,16}$

Using data from the Chronic Disease Registry, we calculated crude prevalence with the 2016 Canadian census population as the denominator. ${ }^{17}$ Individuals remain in the Chronic Disease Registry until they leave the province or die.

\section{Outcomes}

We extracted demographic characteristics, including age, sex, census subdivision (i.e., community of residence) and case source (i.e., CCDSS, laboratory test or both) from the Chronic Disease Registry. We explored the quality of diabetes care using clinical data $\left(\mathrm{HbA}_{\mathrm{lc}}\right.$, low-density lipoprotein [LDL] cholesterol and urine albumin-to-creatinine ratio). We investigated whether the clinical tests were completed within the study cohort year (i.e., Apr. 1, 2015-Mar. 31, 2016) and, for individuals with completed tests, whether the results met indicated targets as recommended in the 2013 clinical practice guideline of Diabetes Canada (previously known as the Canadian Diabetes Association).$^{18}$ For most patients with diabetes, the 2013 guideline recommended that these tests be performed at least once a year, more frequently if targets were not being met. The $\mathrm{HbA}_{1 \mathrm{c}}$ target was $7.0 \%$ or below for most patients, ${ }^{19}$ the $\mathrm{LDL}$ cholesterol target was below $2.0 \mathrm{mmol} / \mathrm{L}$, and the target for urine albumin-to-creatinine ratio was below $2.0 \mathrm{mg} / \mathrm{mmol}^{20,21}$

We explored hospital separations (i.e., departure from hospital for any reason, including discharge, transfer or death) for individuals with diabetes across Newfoundland and Labrador. We identified and categorized hospital separations according to codes in the Canadian version of the ICD-10 for the most responsible diagnosis. ${ }^{22}$

We determined rural and urban status using the Standard Geographical Classification type for the patient's census subdivision (e.g., community) of residence. Each census subdivision is classified as a census metropolitan area, a census agglomeration, a census metropolitan influenced zone or a region with no metropolitan influence. A census subdivision was considered "urban" if it was classified as a census metropolitan area or census agglomeration; otherwise, the census subdivision was considered "rural."23

\section{Statistical analysis}

We calculated descriptive statistics for the demographic characteristics and clinical outcomes of individuals with 
diabetes in Newfoundland and Labrador. We used statistical testing to compare differences between rural and urban dwellers. We used independent-sample $t$ tests or MannWhitney $U$ tests to compare continuous variables and the Pearson $\chi^{2}$ test or the Fisher exact test to compare categorical variables, as appropriate, with $p$ values less than 0.05 defined as significant. We calculated standardized differences for each urban-rural comparison. We excluded from the analyses individuals for whom relevant data (e.g., age, sex, geographic identifier) were missing.

For all analyses, we used IBM SPSS Statistics, version 25 (IBM Corporation) and R (version 4.0.2).

\section{Ethics approval}

The study was approved by the Newfoundland and Labrador Health Research Ethics Board (reference no. 20192750).

\section{Results}

A total of 67898 individuals with diabetes aged 20 years or older were listed in the Chronic Disease Registry as of Mar. 31, 2016. We excluded 1573 individuals with missing data for age, sex or geographic identifier from all analyses. The mean age of those with diabetes was 64.1 (standard deviation [SD] 13.6) years, and $37356(56.3 \%)$ of the sample resided in a rural region (Table 1). Larger proportions of rural than urban residents with diabetes were 65 to 79 years old $(41.2 \%$ v. $37.5 \%)$, were female $(50.2 \%$ v. $48.7 \%)$ and met the diabetes case definition in the Chronic Disease Registry through laboratory tests only $(19.6 \%$ v. $13.1 \%)$. The crude prevalence was greater in rural regions for all age groups and across both sexes.

Table 2 shows the rates of completed clinical tests and on-target results, as well as mean or median test values for

Table 1: Characteristics of patients with diabetes mellitus in Newfoundland and Labrador, fiscal year 2015/16

\begin{tabular}{|c|c|c|c|c|c|c|c|}
\hline \multirow[b]{2}{*}{ Characteristic } & \multicolumn{2}{|c|}{ All patients } & \multicolumn{2}{|c|}{ Urban } & \multicolumn{2}{|c|}{ Rural } & \multirow[b]{2}{*}{$\begin{array}{l}\text { Standardized } \\
\text { difference } \\
(95 \% \mathrm{Cl})\end{array}$} \\
\hline & $\begin{array}{c}\text { No. }(\%)^{\star} \\
n=66325\end{array}$ & $\begin{array}{c}\text { Crude } \\
\text { prevalence, } \\
\%(95 \% \mathrm{Cl})\end{array}$ & $\begin{array}{c}\text { No. }(\%)^{*} \\
n=28969\end{array}$ & $\begin{array}{c}\text { Crude } \\
\text { prevalence, } \\
\%(95 \% \mathrm{Cl})\end{array}$ & $\begin{array}{c}\text { No. }(\%)^{*} \\
n=37356\end{array}$ & $\begin{array}{c}\text { Crude } \\
\text { prevalence, } \\
\%(95 \% \mathrm{Cl})\end{array}$ & \\
\hline Age, yr, mean \pm SD & $64.1 \pm 13.6$ & NA & $63.4 \pm 14.1$ & NA & $64.6 \pm 13.1$ & NA & $\begin{array}{c}0.08 \\
(0.068 \text { to } 0.098)\end{array}$ \\
\hline Age group, yr & & & & & & & $\begin{array}{c}0.112 \\
(0.097 \text { to } 0.127)\end{array}$ \\
\hline $20-34$ & $\begin{array}{l}1791 \\
(2.7)\end{array}$ & $\begin{array}{c}2.10 \\
(2.00 \text { to } 2.20)\end{array}$ & $\begin{array}{l}980 \\
(3.4)\end{array}$ & $\begin{array}{c}1.78 \\
\text { (1.67 to } 1.89)\end{array}$ & $\begin{array}{l}811 \\
(2.2)\end{array}$ & $\begin{array}{c}2.67 \\
\text { (2.49 to } 2.86)\end{array}$ & \\
\hline $35-49$ & $\begin{array}{l}7547 \\
(11.4)\end{array}$ & $\begin{array}{c}7.26 \\
\text { (7.10 to } 7.43)\end{array}$ & $\begin{array}{l}3628 \\
(12.5)\end{array}$ & $\begin{array}{c}6.25 \\
\text { (6.05 to } 6.46)\end{array}$ & $\begin{array}{l}3919 \\
(10.5)\end{array}$ & $\begin{array}{c}8.54 \\
(8.27 \text { to } 8.81)\end{array}$ & \\
\hline $50-64$ & $\begin{array}{c}22545 \\
(34.0)\end{array}$ & $\begin{array}{c}17.65 \\
\text { (17.42 to } 17.88)\end{array}$ & $\begin{array}{l}9867 \\
(34.1)\end{array}$ & $\begin{array}{c}16.26 \\
(15.94 \text { to } 16.58)\end{array}$ & $\begin{array}{l}12678 \\
(33.9)\end{array}$ & $\begin{array}{c}18.91 \\
(18.58 \text { to } 19.24)\end{array}$ & \\
\hline $65-79$ & $\begin{array}{r}26267 \\
(39.6)\end{array}$ & $\begin{array}{c}32.59 \\
(32.20 \text { to } 32.98)\end{array}$ & $\begin{array}{c}10864 \\
(37.5)\end{array}$ & $\begin{array}{c}30.80 \\
(30.22 \text { to } 31.38)\end{array}$ & $\begin{array}{l}15403 \\
(41.2)\end{array}$ & $\begin{array}{c}33.98 \\
(33.44 \text { to } 34.52)\end{array}$ & \\
\hline$\geq 80$ & $\begin{array}{c}8175 \\
(12.3)\end{array}$ & $\begin{array}{c}40.03 \\
\text { (39.17 to } 40.90)\end{array}$ & $\begin{array}{r}3630 \\
(12.5)\end{array}$ & $\begin{array}{c}37.50 \\
(36.28 \text { to } 38.72)\end{array}$ & $\begin{array}{l}4545 \\
(12.2)\end{array}$ & $\begin{array}{c}42.32 \\
\text { (41.09 to } 43.55)\end{array}$ & \\
\hline Sex & & & & & & & $\begin{array}{c}0.03 \\
(0.014 \text { to } 0.045)\end{array}$ \\
\hline Male & $\begin{array}{l}33451 \\
(50.4)\end{array}$ & $\begin{array}{c}16.58 \\
(16.40 \text { to } 16.76)\end{array}$ & $\begin{array}{l}14849 \\
(51.3)\end{array}$ & $\begin{array}{c}14.25 \\
(14.02 \text { to } 14.47)\end{array}$ & $\begin{array}{l}18602 \\
(49.8)\end{array}$ & $\begin{array}{c}19.08 \\
(18.80 \text { to } 19.35)\end{array}$ & \\
\hline Female & $\begin{array}{l}32874 \\
(49.6)\end{array}$ & $\begin{array}{c}15.20 \\
(15.04 \text { to } 15.36)\end{array}$ & $\begin{array}{l}14120 \\
(48.7)\end{array}$ & $\begin{array}{c}12.34 \\
(12.13 \text { to } 12.54)\end{array}$ & $\begin{array}{l}18754 \\
(50.2)\end{array}$ & $\begin{array}{c}18.42 \\
(18.15 \text { to } 18.68)\end{array}$ & \\
\hline Case source & & & & & & & $\begin{array}{c}0.178 \\
(0.162 \text { to } 0.193)\end{array}$ \\
\hline Laboratory only & $\begin{array}{l}11118 \\
(16.8)\end{array}$ & NA & $\begin{array}{l}3789 \\
(13.1)\end{array}$ & NA & $\begin{array}{l}7329 \\
(19.6)\end{array}$ & NA & \\
\hline CCDSS only & $\begin{array}{l}10621 \\
(16.0)\end{array}$ & NA & $\begin{array}{l}4865 \\
(16.8)\end{array}$ & NA & $\begin{array}{l}5756 \\
(15.4)\end{array}$ & NA & \\
\hline Both & $\begin{array}{l}44586 \\
(67.2)\end{array}$ & NA & $\begin{array}{l}20315 \\
(70.1)\end{array}$ & NA & $\begin{array}{l}24271 \\
(65.0)\end{array}$ & NA & \\
\hline
\end{tabular}


Table 2: Rates of completion and on-target results of clinical tests

\begin{tabular}{|c|c|c|c|c|}
\hline \multirow[b]{2}{*}{ Clinical test } & \multicolumn{3}{|c|}{ Group; no. (\%) of patients* } & \multirow[b]{2}{*}{$\begin{array}{l}\text { Standardized difference } \\
\qquad(95 \% \mathrm{Cl})\end{array}$} \\
\hline & $\begin{array}{l}\text { All patients } \\
n=66325\end{array}$ & $\begin{array}{c}\text { Urban } \\
n=28969\end{array}$ & $\begin{array}{c}\text { Rural } \\
n=37356\end{array}$ & \\
\hline \multicolumn{5}{|l|}{$\mathrm{HbA}_{1 \mathrm{c}}$} \\
\hline Test completed & $51007(76.9)$ & $22085(76.2)$ & $28922(77.4)$ & $0.028(0.013$ to 0.043$)$ \\
\hline Result, \%, mean \pm SD $\dagger$ & $7.35 \pm 1.49$ & $7.26 \pm 1.50$ & $7.41 \pm 1.49$ & 0.095 (0.077 to 0.113$)$ \\
\hline Result on target† & $26157(51.3)$ & $11877(53.8)$ & $14280(49.4)$ & $0.088(0.071$ to 0.106$)$ \\
\hline \multicolumn{5}{|l|}{ Low-density lipoprotein cholesterol } \\
\hline Test completed & $45268(68.3)$ & $19878(68.6)$ & $25390(68.0)$ & $0.014(-0.001$ to 0.029$)$ \\
\hline Result, $\mathrm{mmol} / \mathrm{L}$, mean $\pm \mathrm{SD}+$ & $2.41 \pm 0.95$ & $2.36 \pm 0.94$ & $2.46 \pm 0.95$ & $0.107(0.088$ to 0.126$)$ \\
\hline Result on target $†$ & $17175(37.9)$ & $8119(40.8)$ & $9056(35.7)$ & 0.107 (0.088 to 0.125$)$ \\
\hline \multicolumn{5}{|l|}{ Urine albumin-to-creatinine ratio } \\
\hline Test completed & $22676(34.2)$ & $10148(35.0)$ & $12528(33.5)$ & $0.031(0.016$ to 0.047$)$ \\
\hline Result, mg/mmol, median (IQR) $\dagger$ & $1.7(0.8$ to 5.4$)$ & $1.6(0.8$ to 5.1$)$ & $1.7(0.8$ to 5.6$)$ & $0.020(-0.006$ to 0.046$)$ \\
\hline Result on target $†$ & $12429(54.8)$ & $5708(56.2)$ & $6721(53.6)$ & $0.052(0.026$ to 0.078$)$ \\
\hline
\end{tabular}

individuals with diabetes in Newfoundland and Labrador in 2015/16. Among those who had tests, the overall mean $\mathrm{HbA}_{\mathrm{lc}}$ result was $7.35 \%$ (SD 1.49). The mean $\mathrm{HbA}_{\mathrm{lc}}$ was higher among individuals residing in rural communities and the percentage of individuals meeting the recommended $\mathrm{HbA}_{\mathrm{lc}}$ target established by Diabetes Canada was significantly lower for individuals residing in rural regions $\left(\mathrm{HbA}_{1 \mathrm{c}}\right.$ result $7.41 \%$ [SD 1.49] v. 7.26\% [SD 1.50]; $\mathrm{HbA}_{1 \mathrm{c}}$ on target $49.4 \%$ v. $53.8 \%$ ). However, the standardized differences for these relations were small $(0.095$ and 0.088 , respectively).

With respect to LDL cholesterol, although there was no rural-urban difference in the proportion of patients screened, rural residents had significantly higher LDL cholesterol levels and a lower proportion meeting target values than their urban counterparts (mean LDL cholesterol 2.46 [SD 0.95] v. 2.36 [SD 0.94] mmol/L; LDL cholesterol on target $35.7 \% \mathrm{v}$. $40.8 \%)$. The standardized differences for the comparisons of mean LDL cholesterol and proportion of individuals with results on target were small ( 0.107 for both).

A greater proportion of urban than rural residents had testing of urine albumin-to-creatinine ratio $(35.0 \%$ v. $33.5 \%)$ and met the target established by Diabetes Canada $(56.2 \%$ v. $53.6 \%)$. Additionally, there was a significant urban-rural difference in the median urine albumin-to-creatinine ratio values $(1.60$ v. $1.70 \mathrm{mg} / \mathrm{mmol})$, although the standardized differences of all comparisons related to urine albumin-to-creatinine ratio were small $(<0.1)$.

Table 3 presents the rates of hospital separations for individuals with diabetes during fiscal year 2015/16, specifically identifying the reason for hospital admission. A total of $13.7 \%$ of individuals in the sample were admitted to hospital during the study year. A larger number of rural than urban residents were admitted for renal disease ( 14 v. 2), although the percentage of individuals hospitalized for renal disease in both groups was small $(<0.1 \%)$.

\section{Interpretation}

We profiled the current state of diabetes in Newfoundland and Labrador by examining diabetes management using the provincial Chronic Disease Registry. Unlike previous databases, the Chronic Disease Registry incorporates 2 case definitions for diabetes - the CCDSS definition and a laboratory definition - which allows for a more accurate determination of true diabetes prevalence than either source alone.

Importantly, this study identified more individuals with diabetes in Newfoundland and Labrador than the CCDSS (which relies solely on diagnosis codes from hospital and physician visits), suggesting that prevalence may be higher than previously estimated. Specifically, the CCDSS estimated that there were 57060 individuals with diabetes in Newfoundland and Labrador in fiscal year 2015/16 $6^{24}$ (i.e., 9265 fewer individuals than we found using the Chronic Disease Registry). Our larger estimate likely includes patients who received care from primary care physicians paid by salary and alternate payment plans, who represent $35 \%$ of provincial physicians and are not included in the billing data. ${ }^{25}$ As primary care funding models move away from traditional feefor-service structures, organizations must consider the accuracy of their data and how representative they are of actual rates of chronic disease within the population. Future research should examine how these funding structures might affect estimates of chronic disease rates. 
Table 3: Admission to hospital, by category of most responsible diagnosis

\begin{tabular}{|c|c|c|c|c|}
\hline \multirow[b]{2}{*}{ Reason for admission } & \multicolumn{3}{|c|}{ Group; no. (\%) of patients } & \multirow[b]{2}{*}{$\begin{array}{c}\text { Standardized difference } \\
(95 \% \mathrm{Cl})\end{array}$} \\
\hline & $\begin{array}{l}\text { All patients } \\
n=66325\end{array}$ & $\begin{array}{c}\text { Urban } \\
n=28969\end{array}$ & $\begin{array}{c}\text { Rural } \\
n=37356\end{array}$ & \\
\hline Most responsible diagnosis (any)* & $9079(13.7)$ & $3956(13.7)$ & $5123(13.7)$ & $0.002(-0.014$ to 0.017$)$ \\
\hline Cardiovascular disease $†$ & $2299(3.5)$ & $1003(3.5)$ & $1296(3.5)$ & $0.0(-0.015$ to 0.016$)$ \\
\hline Diabetesł & $555(0.8)$ & $245(0.8)$ & $310(0.8)$ & $0.008(-0.007$ to 0.024$)$ \\
\hline Renal disease§ & $16(<0.1)$ & $2(<0.1) \emptyset$ & $14(<0.1)$ & 0.021 (0.005 to 0.036$)$ \\
\hline \multicolumn{5}{|c|}{$\begin{array}{l}\text { Note: } \mathrm{Cl}=\text { confidence interval. } \\
\text { *Includes all codes from the Canadian version of the 10th revision of the International Statistical Classification of Diseases and Related Health } \\
\text { Problems (ICD-10-CA). } \\
\text { †Includes ICD-10-CA codes I00-178 (e.g., ischemic heart disease, hypertensive disease, acute myocardial infarction, heart failure, stroke). } \\
\text { flncludes ICD-10-CA codes E10-E11 (type I diabetes - type II diabetes). } \\
\text { §Includes ICD-10-CA codes N18-N19 (chronic kidney disease - unspecified kidney failure). } \\
\text { ๆThe Fisher exact test was used because of the small sample size. }\end{array}$} \\
\hline
\end{tabular}

We found that more men than women had diabetes in Newfoundland and Labrador, which is in line with the results of previous research. ${ }^{4,24}$ Using data from the Canadian census, we determined that the province has a higher proportion of women than men overall $(51.7 \%)$, and this is consistent in both rural $(51.1 \%)$ and urban $(52.3 \%)$ regions. ${ }^{17}$ However, in our study, slightly more women than men had diabetes in rural areas. This may suggest differing rates of diagnosis for men and women in rural Newfoundland and Labrador, but more research is needed.

The high prevalence rates are particularly noteworthy when rural-urban differences are examined. Although less than half the population (i.e., 47\%) currently resides in rural areas, ${ }^{6}$ the rate of diabetes in these areas accounted for more than half (i.e., $56.3 \%$ ) of the total number of individuals with diabetes in our study. This difference is likely attributable to demographic differences, such as age. The rural population includes a high proportion of aging individuals, and the province has a rural population higher than the national average, ${ }^{6}$ which poses many challenges.

Although the Chronic Disease Registry is relatively new, our findings are similar to those of previous research conducted in Newfoundland and Labrador using other data sources. One study, published in 2010, examined the management of diabetes within a single jurisdiction in the province (the capital city, St. John's). ${ }^{26}$ Attainment of targets for diabetes management indicators recommended by Diabetes Canada were examined, by means of chart audit, in a small sample $(n=160)$ with type 2 diabetes. ${ }^{26}$ In that study, about $48 \%$, $18 \%$ and $21 \%$ of patients met recommended targets for $\mathrm{HbA}_{1 \mathrm{c}}$, LDL cholesterol and blood pressure, respectively. A similar study examining diabetes management in 4 Canadian regions (including St. John's) used chart audits to assess physician adherence to treatment guidelines. ${ }^{27}$ This study found high rates of screening for glycemia and macrovascular disease, but noted that physicians fell short in terms of microvascular screening, management of hypertension and dyslipidemia, as well as delivery of appropriate levels of treatment intensity. ${ }^{27}$ Additional literature related to diabetes in New- foundland and Labrador is more than 2 decades old. These older studies described physician adherence to previous Diabetes Canada clinical practice guidelines and used chart audits to estimate rates of diabetes in the province. ${ }^{28-30}$ They showed higher rates of diabetes than did provincial data sources. They also showed that physicians had poor adherence to clinical practice guideline recommendations, although patients had good blood glucose management. Relative to these previous studies, our findings suggest that physicians had better adherence to clinical practice guidelines but that blood glucose management had worsened.

Our findings show an opportunity for better management of diabetes, in accordance with Diabetes Canada clinical practice guidelines, across the province, especially in rural regions. For most individuals with diabetes, recommended targets are not being met. For example, only half of the individuals in this study had $\mathrm{HbA}_{1 \mathrm{c}}$ less than $7.0 \%$, and the percentage meeting the LDL cholesterol target was even lower (about 38\%). Our findings suggest that a greater proportion of rural than urban residents had diabetes and that these individuals had worse clinical test outcomes, specifically with respect to $\mathrm{HbA}_{\mathrm{cc}}$ and LDL cholesterol.

A higher prevalence of diabetes may be a result of poorer access to health services. ${ }^{31,32}$ In previous research, we identified the breadth of variability that exists in primary health care services across Newfoundland and Labrador and the limited delivery of some of these services. ${ }^{33}$ In recent years, there have been a number of initiatives to develop and strengthen existing supports, such as the 2017 Chronic Disease Action Plan. ${ }^{1}$ This action plan is part of a broader framework establishing goals and objectives to guide the reform of primary health care in the province. ${ }^{2}$ Despite these recent initiatives, continuing research is needed to examine how the availability of primary health care services may be contributing to differences in the management of diabetes across rural and urban regions in the province.

\section{Limitations}

We used the Chronic Disease Registry to profile diabetes across Newfoundland and Labrador. The registry is considered 
more representative of individuals with diabetes in this province than sources such as the CCDSS, because it uses 2 case definitions for diabetes. However, it does not differentiate between type 1 and type 2 diabetes.

Our sample included 5126 individuals (7.7\%) whose diabetes was diagnosed in the study year, 2015/16. These people might not have had time to undergo all recommended tests or establish control of their blood glucose level; nonetheless, we felt it necessary to include them to ensure that we completely characterized diabetes prevalence in the province.

Another limitation was the criterion used to define community size, as categorized by census subdivisions, ${ }^{23}$ which may not necessarily capture all aspects of rurality (e.g., population density, access to health care, economy, culture). Although the definition used was standard for Canadian communities, certain elements that affect access to health care may not be fully captured.

To calculate crude prevalence, we obtained population estimates from Canadian census data. However, given that the data used in this study were from an administrative database, it might have been more appropriate to use the number of individuals with provincial health insurance coverage as the denominator. Data from the Canadian census may underestimate the population of Medical Care Plan registrants by about $6.7 \% .^{34}$

This study may be subject to the quality issues typically associated with the use of secondary data. In addition, to our knowledge, the newly created Chronic Disease Registry has not been tested for completeness and validity, which may have affected the data quality.

Although clinical tests and hospital admissions are important indicators of diabetes management, the available data did not allow us to ascertain other important indicators, such as blood pressure control and frequency of eye and foot examinations. In addition, we had access to only a limited number of demographic variables for the population. Other demographic characteristics, such as race or ethnicity and socioeconomic status, may be related to diabetes management but are not available within the Chronic Disease Registry.

The diabetes cases included in this study were those that had been diagnosed and reported. Our data did not capture cases in which patients failed to report symptoms to a physician or instances in which patients had an incorrect diagnosis or were waiting for a diagnosis.

\section{Conclusion}

This study has shown the need for improved management of diabetes in Newfoundland and Labrador, particularly in accordance with current disease management guidelines. For high proportions of patients with diabetes, recommended targets for $\mathrm{HbA}_{1 \mathrm{c}}$, LDL cholesterol and urine albumin-tocreatinine ratio were not being met. In addition, a greater proportion of individuals with diabetes were living in rural regions than in urban regions, and these individuals had poorer glycemic and cholesterol control than their urban counterparts. Use of the Chronic Disease Registry allowed us to capture a greater number of individuals with diabetes in
Newfoundland and Labrador than has previously been reported by national databases. Given the widespread availability of laboratory data, the CCDSS should consider incorporating these measures into their case definitions. Future research should examine the causes of greater prevalence of diabetes in rural regions, specifically in relation to the availability of primary health care services, and should explore whether this may be associated with poorer diabetes management.

\section{References}

1. The way forward: chronic disease action plan. St. John's: Government of Newfoundland and Labrador, Division of Health and Community Service. Available: www.health.gov.nl.ca/health/chronicdisease/pdf/chronic_illness.pdf (accessed 2019 Dec. 12).

2. Healthy people, bealthy families, healthy communities: a primary bealth care framework for Newfoundland and Labrador 2015-2025. St. John's: Government of Newfoundland and Labrador, Department of Health and Community Services; 2015. Available: www.health.gov.nl.ca/health/publications/ phc_framework.pdf (accessed 2019 Dec. 16).

3. Diabetes Canada Clinical Practice Guidelines Expert Committee; Punthakee Z, Goldenberg R, Katz P. Definition, classification and diagnosis of diabetes, prediabetes and metabolic syndrome. Can 7 Diabetes 2018;42(Suppl 1):S10-5.

4. Diabetes in Canada: facts and figures from a public health perspective. Ottawa: Public Health Agency of Canada; 2011. Available: www.canada.ca/content/dam/phac-aspc/ migration/phac-aspc/cd-mc/publications/diabetes-diabete/facts-figures-faits-chiffres -2011/pdf/facts-figures-faits-chiffres-eng.pdf (accessed 2019 Dec. 12).

5. Diabetes in Newfoundland and Labrador. Toronto: Diabetes Canada; 2019. Available: www.diabetes.ca/DiabetesCanadaWebsite/media/About-Diabetes/ Diabetes\%20Charter/2019-Backgrounder-Newfoundland-and-Labrador.pdf (accessed 2019 Dec. 16)

6. Province of Newfoundland and Labrador. In: Focus on geography series, 2016 Census. Cat no 98-404-X2016001. Ottawa: Statistics Canada; 2017. Available: www12.statcan.gc.ca/census-recensement/2016/as-sa/fogs-spg/Facts-pr-eng. cfm?Lang=Eng\&GK=PR\&GC=10\&TOPIC $=1$ (accessed 2019 Dec. 16).

7. eHealth report. St. John's: Newfoundland \& Labrador Centre for Health Information; 2018. Available: www.nlchi.nl.ca/images/FINAL_NLCHI_-_eHealth_ Report_-Feb_2018.pdf (accessed 2019 Dec. 16).

8. Diabetes Canada Clinical Practice Guidelines Expert Committee; Clement M, Filteau P, Harvey B, et al. Organization of diabetes care. Can 7 Diabetes 2018; 42(Suppl 1):S27-35.

9. Diabetes Canada Clinical Practice Guidelines Expert Committee; Wherrett DK, Ho J, Huot C, et al. Type 1 diabetes in children and adolescents. Can 7 Diabetes 2018;42(Suppl 1):S234-46.

10. Diabetes Canada Clinical Practice Guidelines Expert Committee; Panagiotopoulos C, Hadjiyannakis S, Henderson $M$. Type 2 diabetes in children and adolescents. Can 7 Diabetes 2018;42(Suppl 1):S247-54.

11. Public Health Infobase, Canadian Chronic Disease Surveillance System (CCDSS) disease specific case definitions. Ottawa: Public Health Agency of Canada; 2018, modified Jan. 2020. Available: https://health-infobase.canada.ca/ccdss/publication/ CCDSS_Case_Definitions_DataCubes_v2018_en.xlsx (accessed 2020 Aug. 12).

12. The Canadian Chronic Disease Surveillance System - an overview. Ottawa: Public Health Agency of Canada; 2018. Available: www.canada.ca/en/public-health/ services/publications/canadian-chronic-disease-surveillance-system-factsheet. html (accessed 2019 Dec. 16).

13. Hux JE, Ivis F, Flintoft V, et al. Diabetes in Ontario: determination of prevalence and incidence using a validated administrative algorithm. Diabetes Care 2002;25:512-6.

14. Lipscombe LL, Hwee J, Webster L, et al. Identifying diabetes cases from administrative data: a population-based validation study. BMC Health Serv Res 2018; $18: 316$.

15. Southern DA, Roberts B, Edwards A, et al. Validity of administrative data claim-based methods for identifying individuals with diabetes at a population level. Can 7 Public Health 2010;101:61-4.

16. McBrien KA, Souri S, Symonds NE, et al. Identification of validated case definitions for medical conditions used in primary care electronic medical record databases: a systematic review. 7 Am Med Inform Assoc 2018;25:1567-78.

17. Census subdivisions (CSD) - Newfoundland and Labrador [data file]. St. John's; Government of Newfoundland and Labrador, Department of Finance; 2017. Available: https://stats.gov.nl.ca/Statistics/Topics/census2016/ Excel/Select\%20Age\%20Groups_CSD_NL_2016.xlsx (accessed 2020 July 27).

18. Canadian Diabetes Association Clinical Practice Guidelines Expert Committee. Canadian Diabetes Association 2013 clinical practice guidelines for the prevention and management of diabetes in Canada. Can 7 Diabetes 2013;37(Suppl 1):S1-216. 
19. Canadian Diabetes Association Clinical Practice Guidelines Expert Committee; Imran SA, Rabasa-Lhoret, R, Ross S. Targets for glycemic control. Can 7 Diabetes 2013;37(Suppl 1):S31-4.

20. Canadian Diabetes Association Clinical Practice Guidelines Expert Committee; Mancini GBJ, Hegele RA, Leiter LA. Dyslipidemia. Can 7 Diabetes 2013;37(Suppl 1):S110-6.

21. Canadian Diabetes Association Clinical Practice Guidelines Expert Committee; McFarlane P, Gilbert RE, MacCallum L, et al. Chronic kidney disease in diabetes. Can 7 Diabetes 2013;37(Suppl 1):S129-36.

22. Roche MM, Wang PP. Factors associated with a diabetes diagnosis and late diabetes diagnosis for males and females. 7 Clin Transl Endocrinol 2014;1:77-84.

23. Census dictionary: census metropolitan influenced zone (MIZ). Ottawa: Statistics Canada; modified 2015 Nov. 27. Available: www12.statcan.gc.ca/census -recensement/2011/ref/dict/geo010-eng.cfm (accessed 2019 Dec. 12).

24. Diabetes, crude prevalence rate [data file]. Ottawa: Public Health Agency of Canada; modified 2020 May 7. Available: https://health-infobase.canada.ca/ ccdss/download.aspx? $\mathrm{p}=\mathrm{CCDSS} \& \mathrm{i}=1 \& \mathrm{~s}=5 \& \mathrm{l}=\mathrm{eng}($ accessed 2019 Dec. 12).

25. National Physician Database — payments data, 2015-2016. Ottawa: Canadian Institute for Health Information; 2016.

26. McCrate F, Godwin M, Murphy L. Attainment of Canadian Diabetes Association recommended targets in patients with type 2 diabetes: a study of primary care practices in St John's, Nfld. Can Fam Physician 2010;56:e13-9.

27. Harris SB, Worrall G, Macaulay A, et al. Diabetes management in Canada: baseline results of the group practice diabetes management study. Can 7 Diabetes 2006;30(2):1-7.

28. Worrall G, Fodor G, Butt M. A minimal prevalence study of diagnosed diabetes in Newfoundland and Labrador. Can 7 Public Health 1991;82:104-8.

29. Worrall G, Moulton N. The ratio of diagnosed to undiagnosed diabetes in patients 40 years and older. Can 7 Public Health 1992;83:379-81.

30. Worrall G, Freake D, Kelland J, et al. Care of patients with type II diabetes: a study of family physicians' compliance with clinical practice guidelines. 7 Fam Pract 1997;44:374-81.

31. Kapral MK, Austin PC, Jeyakumar G, et al. Rural-urban differences in stroke risk factors, incidence, and mortality in people with and without prior stroke. Circ Cardiovasc Qual Outcomes 2019;12:e004973.

32. Supina AL, Guirguis LM, Majumdar SR, et al. Treatment gaps for hypertension management in rural Canadian patients with type 2 diabetes mellitus. Clin Ther 2004;26:598-606.

33. Buote R, Asghari S, Aubrey-Bassler K, et al. Primary health care services for patients with chronic disease in Newfoundland and Labrador: a descriptive analysis. CMA7 Open 2019;7:E8-14.
34. Ellison J, Nagamuthu C, Vanderloo S, et al. Estimating chronic disease rates in Canada: Which population-wide denominator to use? Health Promot Chronic Dis Prev Can 2016;36:224-30.

Affiliations: Faculty of Nursing (Lukewich), Division of Community Health and Humanities (Buote, Knight), Discipline of Family Medicine (Asghari), and Primary Healthcare Research Unit, Faculty of Medicine (Aubrey-Bassler, Knight), Memorial University of Newfoundland; Center for Rural Health Studies (Asghari); Health Analytics and Information Services (Knight), Newfoundland and Labrador Centre for Health Information, St. John's, NL; Department of Family Medicine (Mathews), Schulich School of Medicine \& Dentistry, London, Ont.

Contributors: All of the authors were involved in the concept and design of the study. Julia Lukewich (principal investigator and corresponding author) acquired the data, Richard Buote performed the data analysis, and all of the authors contributed to data interpretation. Julia Lukewich and Richard Buote drafted the manuscript, which all authors critically revised for intellectual content. All of the authors gave final approval of the version to be published and agreed to be accountable for all aspects of the work.

Funding: This work was funded by a Faculty of Nursing Research Award and the Seed, Bridge, Multidisciplinary Fund from Memorial University.

Data sharing: The data presented in this study are not available to others. The data were obtained from the Newfoundland and Labrador Centre for Health Information (NLCHI) through a formalized process, which included the establishment of a data-sharing agreement between the 2 parties. Others may request access to these data by contacting the NLCHI directly and submitting a similar request for record-level information for secondary use.

Acknowledgement: The authors acknowledge Dana Ryan for her critical review and formatting of the manuscript for publication.

Supplemental information: For reviewer comments and the original submission of this manuscript, please see www.cmajopen.ca/content/8/4/ E895/suppl/DC1. 